Medical humanities

\section{Should medical humanities be a multidisciplinary or an interdisciplinary study?}

H M Evans, J Macnaughton

\section{Research on interdisciplinarity is essential for the future of medical humanities}

$\mathrm{T}$ he forthcoming annual conference of the Association for Medical Humanities addresses the substantial topic "Medicine and the humanities: towards interdisciplinary practice". The organisers envisage the following objectives for the conference:

- to advance the debate about the practical benefits of medical humanities for clinical practice;

- to focus on the interface between medicine, health care, and a range of humanities disciplines, and

- to create a context in which professionals from a variety of backgrounds can exchange ideas and experiences.

These eminently practice-centred objectives require, of course, to be approached in the spirit of what we might call "interdisciplinary theory", that is, theoretical reflection on interdisciplinarity. Interdisciplinarity is perhaps easier to claim than it is to demonstrate, and putatively interdisciplinary work frequently turns out to be merely multidisciplinary, in the sense of involving relatively disconnected contributions from different disciplines-contributions which, taken in isolation, exhibit no real trace of contact with any other discipline beyond their own. Too often one attends discussions that consist in a succession of speakers presenting essentially discipline based perspectives, with little or no genuinely crossdisciplinary dialogue among them. Medical humanities requires, however, that we attain more than this, for reasons including those that are set out below.

The forthcoming conference is, therefore, both timely and important; its objectives moreover are challenging. For instance, in considering "the interface between medicine, health care, and a range of humanities disciplines" we need to ask whether the interface is a single meeting point of all the disciplines involved or whether a number of different shared boundaries might be involved. Would those sharing a boundary all recognise it to be a boundary, and would they see it in the same terms, for instance, with curiosity, suspicion, lack of interest, bafflement, distaste? Do the parties agree where the boundary lies or might there be contested territory (such as whether a clinical question is wholly the preserve of clinicians or whether its ethical dimensions legitimate the scrutiny of theologians, sociologists, and philosophers)?

Again, a "context in which professionals from a variety of backgrounds can exchange ideas and experiences" must be one that supports at least a partly shared understanding of those experiences, and of the terms in which they are to be reported. This requires some common vocabulary, or at least the hope that such a vocabulary may be sought; but we cannot assume this, and apparently simple terms such as "population", "text", and "duty" are all capable of tripping up discussion where the contributors' disciplinary backgrounds variously include, say, public health, ethnography, history, nursing, and philosophy. Moreover-as we shall explore in greater detail below-terms which have an apparently descriptive meaning within a particular discipline may seem clearly, even extravagantly, metaphorical to the outsider (think of gene "transcription", "messenger" RNA and-in immunology-"helper" cells, for instance).

It is in recognition of these perhaps taxing requirements of genuine interdisciplinarity, then, that we raise the question in this editorial's title: should medical humanities be multidisciplinary or interdisciplinary? For many readers the answer is, clearly, "Both". Other readers may wonder, "What is the difference in practice" and "Does it really matter".

The nature of interdisciplinarity was explored in Howard Brody's keynote talk at last year's Association for
Medical Humanities conference in which he reflected on the process he and his four coauthors went through to write Cholera, Chloroform, and the Science of Medicine: A Life of John Snow. ${ }^{1}$ In writing this biography the team wished to address how Snow managed to excel in both scientific anaesthesia and epidemiology. Their approach was to bring together disciplinary experts in medical practice, epidemiology, history, and biography. Each author drafted appropriate chapters from his own disciplinary perspective then over a period of five years the chapters were revised four times with input from all five coauthors. In the course of this laborious process each coauthor received what Brody called a "mini-apprenticeship" in the others' disciplines. The result, they hoped, was a book in which the insights on Snow's achievements were the more revealing and truthful, coming as it did from a real engagement with his own interdisciplinarity. Brody used this example to make the case for medical humanities as a field which should be characterised by this kind of interdisciplinary study and practice. What exactly is meant by interdisciplinarity, however, and how is it to be distinguished from multidisciplinarity?

\section{WHAT DOES}

\section{"INTERDISCIPLINARITY" MEAN?}

It might be best to start by saying what we take an individual discipline (geology, history, anthropology, physiology, theology, botany and so on) to be for our present purposes. At its simplest, we might regard a discipline as a self conscious field of sustained, systematic inquiry with is own distinguishable broad subject matter, questions, and methods-and, moreover, with a relatively specialised vocabulary supplying the terms by which the field, its subject matter, and its methods are described, and by which its questions are framed. A discipline is also a fairly self contained domain, particularly in the humanities, in the sense that it is not necessarily continuous with others. The subject matters of theology and philosophy have a little in common, but not very much; and economic history can be studied in relative isolation from either and both. No doubt any discipline includes some questions that can be pursued more richly in the light of an awareness of other disciplines, and some disciplines court one another naturally (one thinks of literature and philosophy, for instance), but humanities disciplines have a mutual independence greater than would be found in the natural sciences, where findings in geology are capable of carrying implications for findings in 
microbiology, and vice versa, such that conflicts between them are possible, meaningful, and sufficiently undesirable for both disciplines to need to avoid them in the interests of their own theoretical soundness. The other aspect of a discipline-in science or in humanities-is that it constitutes what Nissani calls a community of experts, whose mutual agreement on fundamentals is a necessary part of their discipline's general coherence. $^{2}$

Interdisciplinarity then concerns the engagement of disciplines one with another, and more particularly with subject matter that somehow both straddles the disciplines and falls between them-aspects of a question which neither might pursue, or even recognise, in isolation. An example is needed to make this clearer-and given the relative novelty of medical humanities, perhaps not surprisingly one finds substantial examples of such questions more easily in other fields.

In a moment we will consider an example from interdisciplinary work in chemical engineering. Before doing so, however, consider that we are trying to describe something more ambitious than simply a familiarity with some mere aspects of two or more disciplines. Common salt is, as seaside gardeners know, highly injurious to the flowering camellia. Chemistry provides the composition and analysis of salt, and plant physiology provides the description of the metabolic disruption salt produces in the camellia bush. Is knowledge of salt's effects on plants part of chemistry, or of plant physiology, or of botany? It seems to belong to all of these, but perhaps early plant physiologists were also to an extent chemists, and indeed might not have been so interested in the disciplinary distinctions as we are today. At any rate, if there ever were an interdisciplinary aspect to understanding why camellias are harmed by common salt, it is not easily discerned now.

A more compelling example concerns how the understanding of a particular industrial problem in chemical engineering has grown from increasingly complex successive "generations" of crossdisciplinary engagement-suggesting that interdisciplinarity consists at least in part in the sophistication and complexity of the ways in which contributing disciplinary insights interact.

Those wishing to improve the mechanics of fluid flow and heat transfer in the production of polymer plastics had, originally, no field of study whatever from which to draw, and industry proceeded empirically. Profitability is, however, like it or not, an engine of inquiry-and mechanical engineers began to make pencil and paper calculations of flow mechanics and heat transfer in isolation from other disciplines. From this "first generation" a second emerged-in which the incorporation of sophisticated theory and models from physics involved so many more variables (and non-linear relationships among them) that pencil and paper calculations became simply impossible, and the rudimentary computers then available became indispensable. The field of inquiry now, of necessity, involved not only chemical engineers and mechanical engineers but also physicists and mathematicians.

The second generation gave way to a third when a form of mathematical analysis (finite element array analysis) made possible powerful computer modelling of processes involving literally millions of variables and the simultaneous solving of equations concerning their behaviour. The interdisciplinary team had been augmented by a specialised partnership between computer scientists and process engineers. The next evolution will, presumably, involve a fourth generation.

This development is held by those involved to be an interdisciplinary one for a number of reasons, each of which suggests an interesting characteristic of interdisciplinary work. The first and simplest reason is that many disciplines are necessarily represented in the team effort. Their various insights and methods are all much needed contributions to the combined project. Second, these insights and methods, crucially, interlock to form a larger methodological picture. Third, those at the "sharp end"- the point of application to the questions and practical problems at issue-see the whole picture, and understand this interlocking. By contrast, those on the periphery may be engaged in self contained research (such as, for instance, further refinements in computer simulation or mathematical modelling) and may remain unaware of the applications which synthesise their individual insights.

To these characteristics of interdisciplinary work we may identify and add others. Perhaps the most important is that of emergence-which is to say that problems and their solutions become discernible only in the engagement of different disciplines, and not within the disciplines themselves in isolation. In the production of polymer plastics, each generation's solution of its own problems makes possible the very conception of problems which will require a further "generation" of interdisciplinary work to solve. The full complexity of fluid mechanics was neither soluble by nor apparent to the pencil and paper generation of chemical and mechanical engineers. Again, while the production of polymer plastics is not itself a problem in physics or in computer science, it entails the answers to problems in physics and could even generate problems which are subsequently appreciated in those disciplines. Such problems have aspects of questions familiar within the constituent disciplines, but they are revealed for what they are in the interdisciplinary context by being approached simultaneously and interrelatedly, not sequentially or separately.

It is important to emphasise that what we are describing here is not simply the practical complexity of any large complicated project-for instance, building a house in which many different kinds of trades are involved. The house building analogy is instructive at the point at which it gives way to what we can call an emergent project of addressing new kinds of building questions. Early mud or daub and wattle houses were perhaps routinely built by single skilled individuals working alone, but a modern masonry house needs many skills which are not often combined in a single individual-the skills of the surveyor, bricklayer, plasterer, joiner, roofer, electrician, plumber, decorator, heating engineer, and so on.

This much could be thought of as simply a multidisciplinary collaboration. Some building activities, however, are possible-even thinkable-only after the elaboration of the basic activities. Only when we are comfortable building houses do office blocks seem possiblecertainly this would seem true of developments requiring changes in thinking. Thus the largest and tallest skyscrapers, whose exterior walls and floors are hung from an endoskeleton of steel framing, represent a different way of thinking about problems and solutions within conventional building, initially taking building beyond the conventional. (The need to build upwards on congested sites, with the currently astronomical land prices, has only recently been recognised.) So this way of thinking is an emergent property perhaps of reaching the limits of conventional practices, and it addresses building problems that could not have arisen in much earlier stages of development of the masonry tradition.

The final characteristic of interdisciplinarity which we offer here is that participants who begin in different disciplines come to share each other's metaphors. Indeed, perhaps the sharing of metaphors which were previously discipline specific, across or among suitably imaginative exponents of other disciplines, is a necessary formative process in the development of an 
interdisciplinary team, and their success in this an index of their having achieved some genuine interdisciplinary understanding. One of the opportunities presented by interdisciplinary activity is, according to Nissani, an intellectual and imaginative "playfulness" which can disclose that which is invisible to the native practitioners of that very discipline. $^{2}$ Also, discipline specific metaphors are perhaps most metaphorical (and also most opaque) to outsiders; insiders increasingly come to use them as straightforward descriptions. Their actual metaphorical nature may, in an interdisciplinary context, re-emerge as a joyous surprise to those whose use of them has grown stale.

Some examples, then, of disciplinary metaphors: civil engineers speak of the loadings which a structure experiences; and they speak also of the behaviour of those structures under load, though clearly not in the same sense as that in which a physicist speaks of the behaviour of particles, or a sociologist of the behaviour of a group, or the economist of the behaviour of a market. The anthropologist and ethnographer may speak of the scripts underlying human behaviour, but not in the sense that an actor would acknowledge. Physicists' talk of the colour of fundamental particles has nothing more in common with our ordinary idea of colour than its having three primary components. Readers may like to consider the metaphors that abound within medicine, including its endless military metaphors for the war against disease; one contributor to this journal has suggested that in psychiatry almost all terms are metaphorical (R Puustinen, personal communication, 2003), and in public health it is amusing to note that the term population invariably means almost any group other than a geographical one! In the project described by Howard Brody, one feels that this feature of interdisciplinarity, the sharing of discipline specific metaphors, was a particularly important one.

\section{DOES INTERDISCIPLINARITY MATTER?}

Howard Brody's experience of writing the biography of Snow suggests that achieving true interdisciplinarity is hard to do and very time consuming. Not many of us like to write by committee and it is very uncomfortable to teach out of one's own discipline. So why do it, and does it matter? The answer is that for the future of our developing field interdisciplinary working is crucial; and the reasons include fundamental concerns such as how we talk about "medical humanities"; how we encourage young academics into the field; and pragmatic concerns, such as how we as individuals engaged in it are funded. As we shall see, these concerns are inextricably linked.

We will take the fundamental concerns first. One way to regard the academic activity that constitutes "the medical humanities" is as an activity bringing together humanities and medical disciplines with a common goal of reflecting on medical practice but with each discipline, be it history, anthropology, or philosophy, essentially retaining its own unique viewpoint and writing from its own literature. This has the advantage that outputs retain the flavour of the writer's disciplinary field and can potentially be of interest to the academic audience within it. Consequently, the individual remains an historian, anthropologist or philosopher in touch with the literature of their field and able to teach and publish within it. This kind of medical humanities must be referred to in the plural. There is, however, a different and more radical form of medical humanities which can be referred to in the singular. Those engaged in the academic activity that this kind of medical humanities entails will be attempting to integrate the viewpoints of whichever disciplines seem most relevant to the question they are asking in their examination of medicine, its knowledge base, assumptions, and practice. They will not be constrained within the viewpoint of historian, anthropologist or philosopher but will build a perspective that is unique to the discipline called "medical humanities". Of course this approach is very risky for academics. Medical humanities specialists, as "interdisciplinarians" under this conception, have to explore literatures outside their home disciplines and may become isolated from that discipline and consequently unable to publish or teach within it.

Despite these risks, medical humanities may have to adopt this approach. Those of us who are at present "medical humanities specialists" are largely doctors, philosophers, literary scholars, and historians who have taken as our subject matter the examination of medicine's nature and goals. If medical humanities is not going to be always dependent upon other disciplines for its recruits and in order to grow and develop as a subject or specialism within medicine, or indeed, within the humanities, we need to encourage young academics into the field whose doctoral studies will make them into interdisciplinarians. There are signs indeed that the research councils, including the Arts and Humanities Research Board (AHRB, soon to become a research council), the Economic and Social Research Council
(ESRC) and the Medical Research Council (MRC), are ready to support genuinely interdisciplinary research. The ESRC is offering interdisciplinary research studentships and postdoctoral studentships in collaboration with the MRC, and the AHRB is currently taking a strong interest in the development of medical humanities by planning a series of workshops to define how it might offer funding opportunities. In a recent discussion paper to facilitate discussion about this workshop series, Professor Geoffrey Crossick, the chief executive of AHRB, emphasised the interdisciplinary nature of medical humanities:

\section{The first need is to identify the range of current activities. In my view we should define these not in terms of the disciplinary character of the arts and humanities input...nor in terms of the goals...but somewhere else: in a clear and significant research engagement from both sides. ${ }^{3}$}

This is an important encouragement to adopt interdisciplinarity, but at the same time we must be aware of the risks. Research applications to the AHRB are still assessed by eight subject panels, none of which would clearly be open to the kind of crossdisciplinary collaborations that exist in medical humanities. In addition, the recent review of the Research Assessment Exercise (by which UK universities obtain government funding tied to research rather than teaching), although paying lip service to interdisciplinary working, did not indicate how within its panel structure such research would be able to succeed to attain the highest star grading. ${ }^{4}$

Medical humanities is by nature an interdisciplinary study and in this way it can make its most effective contributions to knowledge and to teaching. However, engaging in an interdisciplinary subject is by no means without risk in terms of the academic careers of those of us already recruited and for those we might like to attract into the field. There is encouragement now at the highest level to develop structures that will support interdisciplinary research in medical humanities into the future. The risks may be great but the potential for the development of the field is also significant, and despite the risks, we should welcome these opportunities.

\section{ACKNOWLEDGEMENTS}

We are indebted to Dr John Pitmann, School of Engineering, University of Wales Swansea, for extended discussions with Martyn Evans concerning chemical process engineering as an instance of interdisciplinary work. 
$J$ Med Ethics; Medical Humanities 2004;30:1-4.

doi: 10.1136/jmh.2004.000143

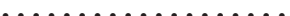

Authors' affiliations

H M Evans, J Macnaughton, Centre for Arts and Humanities in Health and Medicine, University of Durham
Correspondence to: Prof H M Evans \& Dr R J Macnaughton, CAHHM, University of

Durham, 14/15 Old Elvet, Durham DH1 3HP; h.m.evans@durham.ac.uk;

jane.macnaughton@durham.ac.uk

\section{REFERENCES}

1 Vinten-Johansen $\mathrm{P}$, Brody $\mathrm{H}$, Paneth $\mathrm{N}$, et al. Cholera, chloroform, and the science of medicine: a life of John Snow. Oxford: Oxford University Press, 2003.

2 Nissani M. Fruits, salads and smoothies: a working definition of interdisciplinarity. Journal of Educational Thought 1995;29:119-26.

3 Crossick G. Internal briefing paper for participants in an AHRB workshop. London: King's Fund Institute, January 2004.

4 Roberts Sir G. Review of research assessment. London: Higher Education Funding Council for England, 2003.

\section{CALL FOR PAPERS}

\section{Special thematic issue of Medical Humanities: constructions of self in health and illness}

\section{F Rapport, P Wainwright}

J Med Ethics; Medical Humanities 2004;30:4. doi: 10.1136/jmh.2004.000159

$\mathrm{B}$ n his new book, Making Stories: Law, Literature, Life, Jerome Bruner claims that the "self is a perpetually rewritten story". We are all constantly engaged in "self making narrative", in the end becoming "the autobiographical narratives by which we 'tell about' our lives". ${ }^{1}$

Galen Strawson, Professor of Philosophy at the University of Reading, reviewing the book for The Guardian newspaper takes a very different line. Strawson says:

"Every conscious recall brings an alteration, and the implication is plain: the more you recall, retell, narrate yourself, the further you risk moving away from accurate self understanding, from the truth of your being. Sartre is wrong to say that storying oneself is a universal trait, but he's right that it is extremely common, and he is surely right, contrary to the tide of current opinion in the humanities, that the less you do it the better." 2

If, as Strawson claims, the idea of self as constructed through narrative "has come to dominate vast regions of the humanities and human sciences-in psychology, anthropology, philosophy, sociology, political theory, literary studies, religious studies, and psychotherapy", the time is surely ripe for the medical humanities to pay this some attention. Indeed, the division between the technical account of personhood, popular since Locke, and the social construction of self of which Strawson is so critical, might be seen as a kind of paradigm case of the type of problem with which the medical humanities tries so hard to engage. The disagreement between the positions adopted by Bruner and Strawson might be explained, in part, by differences between disciplinary camps. It seems difficult to locate the individual human experience of life, illness, and suffering in the taxonomic account of "self" conceived by the analytic philosophers. Similarly, both the self of the health care practitioner and the notion of self that is at stake in dealing with patients, the self of the patient, as understood within the world of the health care practitioner, appear to demand a fuller account than they have received in the past. The self is something more than just what John Locke called a "conscious thinking thing (whatever substance made up of, whether spiritual or material, simple or compounded, it matters not) which is sensible, or conscious of pleasure or pain, capable of happiness or misery, and so is concerned for itself, as far as that consciousness extends". Is the problem one requiring an attempt at interdisciplinary working?

A special edition of Medical Humanities will be devoted to the problem of the narrative self and its place within medical humanities, seeking to combine contributions from academics within and without the field of the medical humanities, and from health care practitioners from any discipline. Their common concern should be an interest in "constructions" of narrative selves. Papers are invited with regard to:

- our understanding of the self in the broadest context of illness, health and medicine;

- the relationship between self, health, and illness from the perspective of the person or persons experiencing these states;

- the relationship between self, health, and illness as perceived by third parties, and;

- the experience of self as a health care practitioner.

Manuscripts should be sent to the journal in the usual way, but marked "for Special Edition on 'constructions of self" ". They will be forwarded directly to the issue editors. The issue editors welcome informal enquiries prior to submission and can be contacted by email at the addresses given below.

\section{Authors' affiliations \\ P Wainwright, P.Wainwright@swansea.ac.uk \\ F Rapport, F.L.Rapport@swansea.ac.uk}

Correspondence to: The Editors, Medical Humanities, CAHHM, 14/15 Old Elvet, Durham DH1 3HP; medical.humanities@durham.ac.uk

Accepted for publication 25 March 2004

\section{REFERENCES}

1 Bruner J. Making stories: law, literature, life. Cambridge: Harvard University Press, 2002.

2 Strawson G. Tales of the unexpected. The Guardian, 2004 Jan 10. http:// books.guardian.co.uk/review/), 12084,1 118942,00.html (accessed 2 Apr 2004). 